DOI: $10.12957 /$ teias.\%Y.50751

\title{
SEQUÊNCIA FEDATHI PARA MUDANÇA DE PRÁTICA: estudo de caso de uma experiência com o teatro científico
}

\author{
Milínia Stephanie Nogueira Barbosa Felício \\ Daniel Brandão Menezes \\ Herminio Borges Neto
}

\begin{abstract}
Resumo
É preciso estar disposto a mudanças, a fim de ressignificar práticas educativas. O artigo investiga, por meio de estudo de caso, como a Sequência Fedathi pode transformar práticas docentes. Para tanto, observa-se os resultados relatados nas impressões da docente e dos alunos envolvidos, diretamente, com a experiência do teatro científico, realizado em uma escola estadual de Fortaleza. Reflete-se ainda sobre o impacto desse processo nas mediações. A pesquisa é qualitativa, utiliza-se também a pesquisa participante e a metodologia de pesquisa Sequência Fedathi. As metodologias de pesquisa e ensino Sequência Fedathi fazem parte do planejamento e da vivência da prática da professora. A mudança de prática do professor não é apenas uma nova técnica utilizada, o teatro, trata-se de uma forma diferente de fazer, com uma metodologia atrelada e com um objetivo consistente. Recomenda-se, ainda, uma proposta continuada de formação docente a fim de reconstruir concepções de ensino e aprendizagem, que aliem técnicas de ensino a uma metodologia transformadora.
\end{abstract}

ePalavras-chave: sequência fedathi; mudança de postura docente; formação de professores.

\section{FEDATHI SEQUENCE FOR CHANGE IN PRACTICE: case study of a scientific theater experiment}

\begin{abstract}
It is necessary to be willing to change in order to reframe educational practices. The article investigates through a case study how the Fedathi Sequence can transform teaching practices. Therefore, the results reported in the impressions of the teacher and the students involved are observed directly with the experience of scientific theater, held in a state school in Fortaleza. It also reflects on the impact of this process on mediations. The research is a qualitative one, also using participatory research and the Fedathi Sequence research methodology. Fedathi Sequence research and teaching methodologies are part of the planning and experience of the teacher's practice. The change in the teacher's practice is not just a new technique used, the theater, it is a different way of doing things, with a linked methodology, with a consistent objective. A continuous proposal of teacher training in order to reconstruct conceptions of teaching and learning is also recommended, which combines teaching techniques with a transformative methodology.

Keywords: fedathi sequence; change of teaching posture; teacher training.
\end{abstract}

\section{SECUENCIA FEDATHI PARA EL CAMBIO DE PRÁCTICA: estudio de caso de un experimento con teatro científico}

Resumen

Es necesario estar dispuesto a cambiar para replantear las prácticas educativas. El artículo investiga, a través de un estudio de caso, cómo la Secuencia Fedathi puede transformar las prácticas de enseñanza. Por lo tanto, se observan los resultados reportados en las impresiones del docente y los estudiantes directamente involucrados con la experiencia del teatro científico, realizada en una escuela pública de Fortaleza. También 
reflexiona sobre el impacto de este proceso en las mediaciones. La investigación es cualitativa, participativa y también se utiliza la metodología de investigación Secuencia Fedathi. Las metodologías de investigación y enseñanza de Secuencia Fedathi son parte de la planificación y experiencia de la práctica del docente. El cambio en la práctica del profesor no es solo una nueva técnica utilizada, el teatro, se trata de una forma diferente de hacerlo, con una metodología vinculada y con un objetivo constante. También se recomienda una propuesta continua de formación docente para reconstruir los conceptos de enseñanza y aprendizaje, combinando técnicas de enseñanza con una metodología transformadora.

Palabras clave: secuencia fedathi; cambio de postura docente; formación de profesores.

\section{INTRODUÇÃO}

Iniciativas de mudanças na formação de professores já vêm acontecendo, mas ainda se vê o conhecimento saindo do professor e chegando ao aluno de forma diretiva, muitas vezes, encadeado por uma aula expositiva tradicional. É necessário "[...] transformar a sala de aula num ambiente de aprendizagem coletiva, ao invés de um ambiente unidirecional de transferência de conhecimentos" (RONCA et al, 1998, p. 73). Assim, é possível manter o aluno mais afinado com a aula.

Alguns docentes acreditam que sua forma de ensinar é eficiente e acabam por repetir durante anos as mesmas técnicas aprendidas. No entanto, é preciso desenvolver novas habilidades e abrir-se a uma nova postura em sala, independentemente da sua tendência pedagógica. "[...] Críticos de dentro e de fora das escolas têm argumentado, nos últimos anos, que devemos estimular e recompensar o desenvolvimento da habilidade de ensinar" (SCHÖN, 2000, p. 24). Porém, essa habilidade para ensinar trata-se de uma prática docente planejada, ou seja, uma prática pedagógica, algo refletido e maturado com objetivos bem estabelecidos. "[...] Será prática pedagógica quando incorporar a reflexão contínua e coletiva, de forma a assegurar que a intencionalidade proposta é disponibilizada a todos [...]" (FRANCO, 2016, p. 536). Ou seja, também existe um caráter social no ensino.

Essa reflexão pode ser construída durante as graduações de futuros professores com os seus mestres, com leituras, com a autoformação, mas pode ser enfatizada também com a experiência em sala de aula, com algum estudo, com a necessidade real de fazer alguma diferença nos processos de aprendizagem nos jovens, excedendo os conhecimentos cognitivos "construídos" no chão da aula. É necessário refletir sobre “[...] suas teorias práticas à medida que refletem sozinhos e em conjunto na ação e sobre ela, acerca do seu ensino e das condições sociais que modelam as suas experiências de ensino" (ZEICHNER, 1993, p. 22). É necessário ao educador repensar continuamente a sua ação, adaptando-a aos novos estudantes e aos novos contextos sociais.

No contexto de sala de aula, o professor está sempre precisando decidir suas práticas de ensino e, quando reflete e decide como utilizá-las, esse conjunto pode criar uma metodologia de trabalho. Alguns professores implementam propostas didáticas apresentadas como novidade, seja com metodologias ativas, por exemplo, com foco na interação entre os alunos, seja por meio da resolução de problemas para área de Matemática - embora criar e resolver problemas sempre tenha sido uma questão inerente da Matemática. Apresenta-se, portanto, a Sequência Fedathi, uma metodologia com foco no método, nos caminhos do professor para uma atuação em sala de aula a fim de incidir sobre a proatividade do aluno.

A Sequência Fedathi é um método científico aplicado ao ensino, como preconizado por Polya (2006) e Lakatos (1978); foi criado e transposto inicialmente como metodologia de ensino 
pelo Prof. Hermínio Borges Neto, coordenador do Laboratório de Pesquisa Multimeios, da Faculdade de Educação (FACED) da Universidade Federal do Ceará (UFC), "[...] por volta dos anos 1990 e com estudos voltados para as questões da didática da Matemática [...] " (MENEZES, 2018, p. 35). Esta metodologia foi desenvolvida como instrumento norteador da prática do professor para o ensino da Matemática, a fim de organizar os passos do docente, subsidiar sua ação pedagógica e o comportamento em sala de aula; foi ampliado para outras áreas de ensino, guiandose por etapas e fundamentos.

Alguns dos teóricos utilizados para justificar a mudança de postura didática do professor são: Ronca (1988), Schön (2000), Hargreaves (2002), Lopes (2011), Sousa (2015), Franco (2016), Borges Neto (2016), Fontenele (2018) e Menezes (2018). Todos subsidiam a premissa que indica que o professor, ao se deparar com a Sequência Fedathi, coloca-se numa posição de mudança de paradigma pedagógico, dinamizando as atividades desenvolvidas em sua aula.

Tentar-se-á mostrar o diferencial do uso da Sequência Fedathi como metodologia de ensino e suas implicações na prática pedagógica, através da análise do estudo de caso de uma experiência de uma docente da educação básica, em 2017, num concurso anual realizado na Seara da Ciência, da Universidade Federal do Ceará. A experiência explorada neste estudo aconteceu numa escola de ensino médio da rede estadual de ensino do Ceará, localizada em Fortaleza, com a participação de 21 jovens. Naquela ocasião, a professora utilizou a Sequência Fedathi por meio da estruturação e do desenvolvimento de um teatro científico. O objetivo do concurso é incentivar a interação entre arte e ciência nas escolas da educação básica, valorizando professores e motivando alunos por meio de apresentações em grupo e da prática da arte performática. A participação resultou em seis indicações e três prêmios no evento, inclusive o prêmio principal da edição: o melhor espetáculo (Júri Oficial).

A pergunta que permeia esse trabalho é: como a Sequência Fedathi pode transformar práticas docentes? Define-se como objetivo deste artigo - escolhido segundo o instrumento de categorias de domínio cognitivo de aprendizagem, Taxonomia de Bloom, a nível de análise, já que procura-se "[...] subdividir o conteúdo em partes menores com a finalidade de entender a estrutura final"( FERRAZ; BELHOT; 2010, p. 426) - investigar como a Sequência Fedathi pode transformar as práticas docentes, conhecendo os resultados nas impressões da docente e dos alunos participantes da pesquisa. Como resultado preliminar, uma vez que a docente já estudava a metodologia de ensino por quase um ano, afirma-se que a metodologia permitiu uma mudança efetiva na atividade docente, não se limitando apenas a um novo método para a aula. As mudanças serão exploradas no decorrer do artigo.

Inicialmente, será descrito, na seção Rompimento com a aula expositiva tradicional: mudanças de prática, como a Sequência Fedathi causou uma "ruptura didática" na visão da docente, a partir do momento em que passou a implementá-la em sua prática pedagógica. Em seguida, nas seções Sequência Fedathi como metodologia de ensino e Sequência Fedathi como metodologia de pesquisa apresentar-seá, um breve resumo da Sequência Fedathi como metodologia de ensino e de pesquisa. Posteriormente, na seção Procedimentos metodológicos, será apontado o percurso da pesquisa. E, finalmente, na seção Resultados e Análises, serão feitas as investigações por categorias. 
DOI: $10.12957 /$ teias.\%Y.50751

\section{ROMPIMENTO COM A AULA EXPOSTIVA TRADICIONAL: MUDANÇA DE PRÁTICA}

A prática tradicional refere-se ao domínio absoluto do professor sobre a situação de aula. “[...] Em geral, a literatura didática conceitua aula expositiva como uma comunicação verbal estruturada, utilizada pelos professores com o objetivo de transmitir determinados conteúdos aos alunos" (LOPES, 2011, p. 41). De certa forma, ela pode ser dialógica, ou seja, a aula expositiva pode, sim, estimular o pensamento criador e a capacidade crítica dos alunos. Portanto, o artigo propõe, também, refletir sobre a forma tradicional e recorrer a uma nova técnica ou ressignificação da aula expositiva.

O professor pode ter momentos de reflexão da sua prática, mas é na imersão, no processo de implementação de mudanças, que realmente a transforma. Não se trata apenas da maneira de ensinar, mas, acima de tudo, da sua disposição de mudar, inovar, refletir sobre novas possibilidades pedagógicas e atuar previamente na transformação de seus alunos. "[...] A ausência da reflexão, o tecnicismo exagerado, as desconsiderações aos processos de contradição e de diálogo podem resultar em espaços de engessamento das capacidades de discutir/propor/mediar concepções didáticas" (FRANCO, 2016, p. 544). Nesse caso, o professor não se dispõe a mudar sua forma de ensinar. De certo modo, não se compreende uma mudança de forma brusca: o professor precisa sentir essa necessidade em sua rotina profissional. E quando essas mudanças acontecem?

Pode-se dizer que uma prática docente é também prática pedagógica quando está incorporada de intencionalidades. "[...] há práticas docentes construídas pedagogicamente e há práticas docentes construídas sem a perspectiva pedagógica, num agir mecânico que desconsidera a construção do humano" (FRANCO, 2016, p. 536). As práticas pedagógicas não têm o intuito de adicionar alegorias na sala de aula, mas, sim, uma nova forma de fazer.

A prática docente configura-se como prática pedagógica quando esta se insere na intencionalidade prevista para sua ação. Assim, um professor que sabe qual é o sentido de sua aula em face da formação do aluno, que sabe como sua aula integra e expande a formação desse aluno, que tem a consciência do significado de sua ação, tem uma atuação pedagógica diferenciada: ele dialoga com a necessidade do aluno, insiste em sua aprendizagem, acompanha seu interesse, faz questão de produzir o aprendizado, acredita que este será importante para o aluno (FRANCO, 2016, p. 541).

Nesse caso, o professor compreende a força do seu trabalho e sua responsabilidade diante do aprendizado dos alunos, acredita que pode fazer diferença e investe suas ações com esse propósito, configurando uma mudança no agir docente.

Os efeitos positivos dessas mudanças impulsionarão o professor a continuar investindo em novas atitudes. Para começar a ver os resultados, o professor precisa acreditar e estar estimulado com esse novo "fazer pedagógico", a fim de alcançar o estudante. Mais ainda: o professor precisa sentir-se motivado a fim de estimular o estudante e, para isso, precisa ter um bom relacionamento com ele. É o que propõe Pinheiro (2016) quando aborda a questão da relação vincular entre os participantes do processo de ensino-aprendizagem. A relação vincular diz respeito à criação de um elo para favorecer a boa interação nos processos de mediação, não fazendo pelo aluno o que precisa ser feito por ele, mas orientando-o para o seu progresso, dentro de uma cordialidade e da colaboração entre os membros, aluno-aluno ou aluno-professor. Conforme Schön (2000), Dewey afirma que o aluno precisa perceber por si mesmo o que se ensina a ele, vendo o que precisa ver. 
“[...] Os alunos aprendem fazendo, e os instrutores são mais orientadores que professores" (SCHÖN, 2000, p. 27). O professor precisa se policiar para não dar respostas prontas para os alunos durante a mediação, precisa ajudá-los a passar pelos processos, tentando construir o conhecimento.

De acordo com Schön (2000), o professor coloca-se em "reflexão-na-ação" quando algum elemento surpresa surge em sala de aula, forçando-o a investir e reinvestir nessa situação inesperada. Ele não se conhece na ação, já que essa prática não é habitual para ele; ele não se encaixa na categoria de se "conhecer-na-ação", pois esta categoria ultrapassa as fronteiras do que lhe é familiar, ressignificando sua ação, afetando o seu fazer cotidiano, promovendo uma mudança em sua prática docente.

"O que diferencia a Sequência Fedathi de uma aula tradicional não é a metodologia em si, mas a postura que o professor assume diante da turma na condução da atividade, seja ela resolução de problemas, aula expositiva ou de resolução de exercícios" (SOUSA, 2015, p. 231). O professor pode atuar na perspectiva expositiva, mas esta deve ser dialógica. A Sequência Fedathi "[...] sugere a mudança na condução da aula pelo professor" (MENEZES, 2018, p. 41).

\section{SEQUÊNCIA FEDATHI COMO METODOLOGIA DE ENSINO}

A Sequência Fedathi como metodologia de ensino pretende nortear os passos do professor em sua prática. Foi elaborada por Hermínio Borges Neto após voltar de seus estudos em pósdoutorado na França. Fedathi faz referência às iniciais de seus três filhos: Felipe, Daniel e Thiago. Um dos motivos que lhe impulsionou para a construção da metodologia foi o baixo desempenho observados nos cursos de Matemática da Universidade Federal do Ceará, enquanto foi professor.

Quando o professor for aplicar a Sequência Fedathi, deverá fazer um planejamento minucioso, considerando os possíveis caminhos que os alunos irão investigar, a fim de evitar se colocar em situações para as quais não esteja preparado.

Para iniciar uma aula, é preciso sondar o Plateau ${ }^{1}$ da turma, a fim de considerar em que nível os alunos se encontram, decidindo a base comum que possa ser um elemento desencadeador da aula. Nas observações das experiências pedagógicas descritas neste artigo, o Plateau foi sondado considerando que os elementos matemáticos do texto trabalhado se referiam a conteúdos do ensino fundamental conhecidos pelos alunos. Estes, por sua vez, ainda estavam motivados e dispostos a envolver-se nas atividades pertencentes ao teatro científico, identificando que as escolhas do professor eram adequadas.

O professor precisa investigar os conhecimentos prévios dos alunos, ou seja, os saberes que eles possuem, considerando também os pré-requisitos do conteúdo, isto é, as habilidades necessárias para a construção do conhecimento, a fim de poder iniciar essa nova problemática de maneira a chegar ao novo conhecimento sem grande lacuna, em relação ao que o aluno já sabe, partindo de algo comum.

\footnotetext{
${ }_{1}$ Plateau, segundo a Sequência Fedathi, é o nível de conhecimento prévio ou pré-conceitos do sujeito em relação ao domínio do conteúdo.
} 
DOI: $10.12957 /$ teias.\%Y.50751

\section{SEQUÊNCIA FEDATHI: ETAPAS E FUNDAMENTOS}

Como método científico, a vivência pedagógica da Sequência Fedathi é caracterizada por quatro etapas: Tomada de Posição (ou Apresentação do Problema) ${ }^{2}$, Maturação, Solução e Prova. Para a primeira etapa, apresenta-se um problema inicial, ou uma questão a ser discutida, que seja capaz de prender a atenção e o interesse dos alunos, estimulando a interpretação do mundo, para isso, o problema, ou a questão, precisa ser planejado cuidadosamente, considerando o Plateau. "[...] Cabe ao professor, obviamente, oferecer quadro de referências básicas e transmitir valores. Mas, acima de tudo, cabe a ele ser desafiador. Ele deve, partindo do perfil de sua classe naquele semestre, conduzi-la sempre a uma etapa mais ousada" (RONCA et al, 1998, p.70). Ou seja, o problema precisa estar num nível adequado para que os alunos não desistam, e um dos critérios para isso é que não sejam fáceis ou difíceis demais.

É importante lembrar que tão importante quanto escolher o desencadeamento inicial para a Tomada de Posição é saber como se irá problematizar para o aluno. A próxima etapa é a Maturação. Na Maturação, o professor se encarregará de ajudar o(s) aluno(s) a raciocinar(em) sobre o problema. Para isso, poderá utilizar a pedagogia "mão no bolso", refletida na Sequência Fedathi como o ato de dosar sua interferência na construção do aluno, fazendo analogia ao ato do professor colocar a mão no bolso, para não cair na tentação de pegar a caneta e realizar a questão para o estudante. Desse modo, o professor precisa ser experiente, auxiliando os alunos e evitando dar respostas que os privem do momento de construção, permitindo interferências diferentes de acordo com a necessidade de cada aluno.

O professor pode fazer analogias e mostrar situações, para que o aluno consiga visualizar de uma nova forma seus resultados. "[...] O professor deve dar oportunidade para que os alunos fiquem independentes e, caso haja perguntas oriundas dos alunos sobre alguma passagem para solucionar a questão proposta, poderá utilizar-se de contraexemplos e aplicações em outros contextos" (MENEZES, 2018, p. 45). Quando se fala em contraexemplo, procura-se questionar o aluno, seja para que ele ratifique a validade da sua hipótese, seja para rejeitar por meio da reflexão a nova situação dada e seguir por outro caminho. Deve-se também valorizar o erro, para ajudar o aluno a superá-lo. A relação vincular entre os participantes promove um menor medo de errar, e, portanto, um maior debruçamento do estudante, que se sente mais à vontade em experimentar.

$\mathrm{Na}$ Solução, o aluno (ou os alunos), acreditando que já se aproxima dos procedimentos e resultados adequados ao problema, apresenta suas respostas encontradas e escuta de seus colegas os caminhos escolhidos por eles, nos quais é possível identificar e reconhecer quais soluções foram mais rápidas, quais ele consegue acompanhar ou se estão todas muito parecidas. O professor precisará auxiliar o aluno a identificar em que ponto sua solução pode ter falhado, o que falta para concluí-la ou até se essa resolução já se encontra sistematizada, chegando na Prova.

A Prova, ainda podendo haver interações no grupo (professor e alunos), é a etapa em que, a partir de uma das soluções apresentadas na etapa anterior, se finaliza a solução, sistematizando o

\footnotetext{
${ }^{2}$ Historicamente, "Apresentação do Problema" era o nome da primeira etapa da Sequência Fedathi. Com o tempo, no sentido de postura, atitude docente, foi formalizado para Tomada de Posição.

3 “'.... Como elaboração de teoria, a pedagogia 'mão no bolso' transcorre as fases da Sequência Fedathi, dando elementos teórico-práticos à mediação do professor na reflexão dos alunos, no intuito de que estes consigam organizar e expressar seus pressupostos, para tentar solucionar o problema proposto, organizados individualmente ou em grupo, tendo em vista o nível de dificuldade da atividade, tempo disponível e outros elementos necessários ao planejamento da sessão didática" (SANTANA, 2018, p.16).
} 
conteúdo, valorizando os caminhos traçados pelos estudantes. Deve-se ter o cuidado para não focar apenas no aluno que chegou mais perto da formalização, existe um esforço construtivo para que todos entendam os caminhos de resolução do problema.

Para mediação das etapas, o professor deve planejar com cuidado todos os conceitos trabalhados na Sequência Fedathi, seja a "pedagogia mão no bolso", o "acordo didático", a "pergunta", o "contraexemplo" ou a concepção de "erro". O professor fedathiano ${ }^{4}$ precisa estar preparado para mediar sua aula.

[...] a mediação docente constitui um processo permanente que envolve não só o conteúdo em si, mas as relações e o envolvimento que os sujeitos (educador e educandos) estabelecem com o mesmo, permitindo, especialmente, que os alunos se sintam estimulados e partícipes ativos do processo de ensinoaprendizagem (TREVIZAN, GEBRAN, GUIMARÃES, 2017, p. 184-185).

Pela mediação, o mediado adquire os pré-requisitos cognitivos necessários para aprender, beneficiar-se da experiência e conseguir modificar-se. A mediação deve ser um processo deliberado, intencional, que estimula a busca do significado (PINHEIRO, 2018, p.45).

Duas interpretações cabem sobre o termo "mediar" na Sequência Fedathi: uma significa agir na qualidade de mediador; a outra, dividir ao meio, repartir em duas partes iguais. O professor intervém nos processos que facilitam o aprendizado do aluno: orientando, mas também provocando no estudante a responsabilidade pelo seu processo de aprendizado. Os dois personagens atuam juntos com um objetivo comum: chegar à solução do problema. Não existe mediação sozinho. Trata-se de um processo colaborativo no qual a responsabilidade é dividida. Para atuar com essas concepções, o professor precisa reduzir a ênfase dada aos processos expositivos tradicionais de ensino, favorecendo a dialogicidade em sala de aula.

Verifica-se, portanto, a importância de atrelar a prática docente a essa metodologia, seja por meio do teatro, ou de uma aula expositiva, já que é possível trabalhar a capacidade autônoma do aluno, tão importante para a construção de sua aprendizagem. Isso não significa que o professor estará fora desse processo, muito pelo contrário: o professor deverá estar sempre atento para ser o orientador do aluno.

\section{SEQUÊNCIA FEDATHI COMO METODOLOGIA DE PESQUISA}

A Sequência Fedathi, vista como um método de pesquisa, é uma interpretação mais recente da Sequência Fedathi, agora fundamentada numa prática do professor-pesquisador. É apresentada inicialmente em Menezes (2018) e utilizada nas pesquisas de Barbosa (2020) e Xavier (2020), congressos e artigos acadêmicos.

Como a Sequência Fedathi é o método científico aplicado à situação de ensino, o que fazemos nessa situação é reinterpretar suas quatro etapas, apenas readaptando, com foco no planejamento do professor-pesquisador.

A primeira etapa é a Tomada de Posição (ou Apresentação do Problema), e indica: propósito, justificativa, relevância e função. Na pesquisa ou no planejamento do professor é

\footnotetext{
${ }^{4}$ Aquele que atua com a prática pedagógica da Sequência Fedathi.
} 
necessário identificar o que se pretende alcançar, o que se quer procurar, e o porquê, para planejar as ações.

A Maturação apresenta-se como o debruçamento que se faz para melhor entender o Problema, para "[...] um controle de busca pela resolução" (MENEZES, 2018, p. 26). Portanto, é o planejamento, a lapidação dos objetivos. Faz referência à maturação, à busca, à descoberta, a um desenvolvimento de modelo ou a uma modelização que responda o que se propôs a realizar na primeira etapa, ou seja, como alcançar a resposta.

$\mathrm{Na}$ Solução, o pesquisador colocará em ação seu planejamento, procurando sua validação. Se compara com a Solução da Sequência Fedathi como metodologia de ensino, quando o aluno apresenta uma solução; nesse caso é o professor-pesquisador que vai a campo em sua investigação "[...] e averigua se houve mudança de comportamento ou atitude diante de determinado problema que foi trabalhado" (MENEZES, 2018, p. 27). É nesse momento que os instrumentos metodológicos são colocados em ação. Pesquisa participante, entrevistas, aplicações de sessões didáticas. É o contato direto com o objeto de estudo.

Enfim, na Prova, os resultados são avaliados e são realizadas “[...] as análises das aplicações” (MENEZES, 2018, p. 27), extraindo as principais conclusões da pesquisa.

\section{PROCEDIMENTOS METODOLÓGICOS}

O principal objetivo da pesquisa foi investigar como a Sequência Fedathi pode transformar as práticas docentes, dentro da experiência do professor com o teatro científico, conhecendo os resultados a partir das impressões da docente e dos alunos participantes da pesquisa; foi necessário buscar evidências que respondessem aos questionamentos levantados. Dessa forma, a metodologia de pesquisa Sequência Fedathi foi utilizada para o planejamento da pesquisa. A Apresentação do Problema, primeira parte da pesquisa, compreendeu a revisão de literatura e procurou no repertório bibliográfico elementos da Sequência Fedathi, conteúdos sobre mudança de prática docente e quebra do ensino expositivo tradicional.

$\mathrm{Na}$ Maturação, foi possível identificar o controle de busca, o planejamento e o método do pesquisador para responder ao questionamento. Compreende-se a pesquisa como abordagem de cunho qualitativo, delineada como estudo de caso, já que os estudos de casos "[...] são métodos preferidos quando: (a) as questões 'como' ou 'por que' são propostas; (b) o pesquisador tem pouco controle sobre os eventos; (c) o enfoque está sobre um fenômeno contemporâneo no contexto da vida real" (YIN, 2010, p. 23).

$\mathrm{Na}$ Solução, terceira etapa da pesquisa, como o pesquisador era o próprio professor da experiência com o teatro, colocou-se em ação a observação participante. "[...] A observação participante, ou observação ativa, consiste na participação real do conhecimento na vida da comunidade, do grupo ou de uma situação determinada" (GIL, 2008, p. 105). A pesquisa participante

[...] deve ser compreendida como um repertório múltiplo e diferenciado de experiências de criação coletiva de conhecimentos destinados a superar a oposição sujeito/objeto no interior de processos que geram saberes e na sequência das ações que aspiram gerar transformações a partir também desses conhecimentos (BRANDÃO, STRECK, 2006, p. 12).

A experiência foi realizada numa escola de ensino médio de tempo integral de Fortaleza, que no período possuía doze turmas, oito em tempo integral e quatro regulares. Não foi escolhida 
uma turma específica para a participação da experimentação, os alunos foram convidados por sala para se reunirem depois da aula. Vinte e um alunos participaram efetivamente da experiência.

Os depoimentos foram fontes de evidência para coleta de dados, a fim de descrever e interpretar as percepções subjetivas dos envolvidos. Os participantes deram seus depoimentos por meio de redes sociais e foram avisados sobre o motivo pelo qual estavam falando sobre a experiência. "[...] $\mathrm{Na}$ pesquisa social, estamos interessados na maneira como espontaneamente as pessoas se expressam e falam sobre o que é importante para elas e como pensam sobre suas ações e ações dos outros" (BAUER, GASKELL, 2015, p. 21).

$\mathrm{Na}$ quarta etapa, Prova, os dados foram categorizados baseados na subjetividade do professor-pesquisador em relação às ações que compreendem a mediação e a utilização da metodologia de ensino e de pesquisa, assim como a subjetividade nos depoimentos dos alunos envolvidos. Os dados foram interpretados e serão mostrados na próxima seção.

\section{RESULTADOS E DISCUSSÕES}

Os resultados foram discutidos pelo pesquisador segundo as categorias: comportamentos das práticas durante a metodologia de ensino Sequência Fedathi, compreendendo a mediação e as etapas; a utilização do planejamento do professor pela metodologia de pesquisa Sequência Fedathi; e a subjetividade dos alunos nos depoimentos sobre os processos do teatro.

\section{Metodologia de ensino Sequência Fedathi}

Devido à diversidade de elementos da sequência, esta categoria foi dividida em duas subcategorias: mediação da sequência, compreendendo os fundamentos; e etapas da sequência.

\section{Mediação da sequência}

A professora fez o planejamento de sua mediação com os alunos, mas necessitou alterá-lo algumas vezes durante o processo. Inicialmente, percebeu-se que, até para criar o nome para a equipe, o grupo precisaria ser mais colaborativo, e o propósito bem programado; buscou-se fazer com que os alunos entendessem por meio dessa atividade o objetivo de estarem no grupo. Inicialmente, a escolha foi deixada de forma aberta. Começaram a surgir nomes não pertinentes ao propósito do teatro. Então, foi perguntado: "Mas esses nomes fazem referência a nós e à nossa proposta de aliar ciência?", "Vamos falar de Matemática, por que não caracterizá-la nesse sentindo?”. Então, vários nomes foram aparecendo, resgatando o propósito da Matemática envolvida e aliando a este propósito a ideia que tinham do teatro - uma forma de sair da seriedade das aulas. Eles descobriram mais tarde que o teatro se tornou tão sério como as notas das avaliações.

Finalmente, optaram por: "Pirraios" ( $\pi$ rraios), "Pi" e "Raio", fazendo alusão aos elementos matemáticos e à palavra "pirralhos", que significa menino, ou criança, uma vez que se tratava inicialmente de uma brincadeira. Esta estratégia criou uma identificação do grupo. A identidade do grupo é importante, pois configura a compreensão do coletivo, da equipe em que se está atuando. Nesse caso, a professora utilizou perguntas para demostrar aos alunos o propósito do teatro, construindo assim o nome do grupo. 
Os alunos sentiram dificuldade de escolher o texto para a peça, e, devido ao tempo curto, a própria professora indicou para eles o livro "O homem que calculava" de Malba Tahan", especificamente, os três primeiros capítulos que abordam o conhecido problema dos 35 camelos, mas o material original para apresentação foi readaptado quando a professora pensou: "Por que não adaptar esse texto para uma realidade mais próxima dos alunos, valorizar a cultura e deixar que eles façam uma transformação no texto?”. Assim, eles poderiam ler e refletir durante a adaptação, valorizando a linguagem própria tão conhecida dos cearenses, prestigiando seu aporte cultural.

O professor terá de ser capaz de assistir os alunos para que encontrem o significado das suas múltiplas e diversas experiências. Por esse motivo, o seu ensinamento deve estar conectado com os conhecimentos prévios dos alunos, bem como com a realidade que estão vivenciando. $\mathrm{O}$ ensino não pode estar desvinculado das suas experiências, nem alheio a suas preocupações. (MARCHESI, 2002, p. 23)

Com a intenção de aliar à cultura o que de mais incorporado há na linguagem, seja no modo de falar ou de se vestir, a interessante história árabe foi transformada numa trajetória cearensês $s^{7}$ a fim de dar aos alunos a oportunidade de reconstruírem o contexto com um novo olhar, dentro do sertão nordestino, utilizando a criatividade, a inventividade. $O$ texto foi passado pelo grupo a fim de mudar cada palavra e fazer adaptações, indo de "O Homem que calculava" para "O cearense que calculava". "O problema dos camelos"? Tornou-se "O problema dos jumentos".

Para Branca (2007), é muito comum no teatro moderno a criação em grupo: um trabalho feito por várias pessoas, orientadas pelo diretor, neste caso, a própria professora. Trata-se, portanto, de um trabalho colaborativo. "[...] As crianças nas salas de aula não podem colaborar a menos que seus professores também colaborem” (HARGREAVES; O'CONNOR, 2018, p. 2, tradução nossa). O professor não pode deixar que os alunos criem sozinhos, é preciso acompanhar, construir juntos com um objetivo comum.

Além de original, a história tornou-se cômica. Alguns elementos foram pesquisados, seja de Português, História ou Geografia, a fim de transpor o texto árabe para a cultura local. Na tabela 1, pode-se ver algumas transformações feitas no texto:

\footnotetext{
5 "O homem que calculava" conta a história de um árabe que usa a matemática para resolver qualquer tipo de problema. ${ }^{6}$ Malba Tahan é o pseudônimo de Júlio César de Mello e Souza, percursor da Educação Matemática no Brasil que valoriza o raciocínio de resoluções de problemas frente ao uso mecânico de fórmulas.

7 O termo "cearensês" diz respeito a uma forma cearense de falar, com uso de gírias e expressões específicas da linguagem enraizada do povo do Ceará.
} 
Tabela 1: Algumas adaptações do texto

\begin{tabular}{|c|c|}
\hline $\begin{array}{l}\text { O homem que calculava - (Problema dos Camelos) de } \\
\text { Malba Tahan (2008) }\end{array}$ & $\begin{array}{l}\text { O cearense que calculava - (Problema dos Jumentos) } \\
\text { dos Pirraios/ Magalhães et. al (2017) }\end{array}$ \\
\hline $\begin{array}{l}\text { "Voltava eu, certa vez, ao passo lento do meu camelo, } \\
\text { pela estrada de Bagdá, de uma excursão à famosa cidade } \\
\text { de Samarra, nas margens do Tigre, quando avistei, } \\
\text { sentado numa pedra, um viajante, modestamente } \\
\text { vestido, que parecia repousar das fadigas de alguma } \\
\text { viajem" (p. 15). }\end{array}$ & $\begin{array}{l}\text { "NARRADOR: Voltava Tião, bem devagarin ao lado de } \\
\text { Policarpo (seu jumento), de um passeio ao Juazeiro do } \\
\text { Norte, quando estava passando próximo ao rio Jaguaribe, } \\
\text { avistou na beirada um cabra malvestido que parecia estar } \\
\text { acabado de uma viagem..." (p.4) }\end{array}$ \\
\hline $\begin{array}{l}\text { "Voltava eu, certa vez, ao passo lento do meu camelo, } \\
\text { pela estrada de Bagdá, de uma excursão à famosa cidade } \\
\text { de Samarra, nas margens do Tigre, quando avistei, } \\
\text { sentado numa pedra, um viajante, modestamente } \\
\text { vestido, que parecia repousar das fadigas de alguma } \\
\text { viajem" (p. 15). }\end{array}$ & $\begin{array}{l}\text { "NARRADOR: Voltava Tião, bem devagarin ao lado de } \\
\text { Policarpo (seu jumento), de um passeio ao Juazeiro do } \\
\text { Norte, quando estava passando próximo ao rio Jaguaribe, } \\
\text { avistou na beirada um cabra malvestido que parecia estar } \\
\text { acabado de uma viagem..." (p.4) }\end{array}$ \\
\hline $\begin{array}{l}\text { "Asseguro-vos - pelas relações que mantenho, pois sou } \\
\text { bagdáli - que não vos será difícil obter lugar de destaque } \\
\text { junto ao glorioso califa Al Motacém (nosso amo e } \\
\text { senhor). Podeis talvez exercer o cargo de vizir-tesoureiro } \\
\text { ou desempenhar as funções de secretário da Fazenda } \\
\text { muçulmana.- Se assim é, ó jovem - respondeu o } \\
\text { calculista -, não hesito. Vou contigo para Bagdá" (p.19) }\end{array}$ & $\begin{array}{l}\text { “TIÃO: Garanto a ti, pelas relações que tenho, pois sou } \\
\text { nordestino arretado, que a ti não será difícil obter lugar de } \\
\text { destaque junto ao nosso coronel Camilo. } \\
\text { FRANCISCO: Oxel Vou contigo para Juazeiro?' (p.๑). }\end{array}$ \\
\hline $\begin{array}{l}\text { "Deverias receber meu amigo, a metade de } 35 \text {, isto é, } 17 \\
\text { e meio. Receberás a metade de } 36 \text {, portanto, } 18 . \text { Nada } \\
\text { tens a reclamar, pois é claro que saíste lucrando com esta } \\
\text { divisão" (p.23). }\end{array}$ & $\begin{array}{l}\text { "FRANCISCO: Deverias receber muié, a metade de } 35 \text {, } \\
\text { isto é, } 17 \text { e meio. Receberás a metade de } 36 \text {, portanto } 18 . \\
\text { Nada tens a reclamar, pois é claro que tu lucrarás com } \\
\text { esta divisão" (p.8). }\end{array}$ \\
\hline
\end{tabular}

Fonte: Elaborado pelos autores, 2020

Observa-se que o traço forte da regionalidade expressa no texto foi construído com os alunos, que trataram de carregar o texto com esse propósito, refletindo até sobre a política ao tratar do coronel, fazendo referência ao governador do estado do Ceará de então.

O interesse em participar, assim como a relação vincular, contribuiu com o processo do teatro. Os alunos não tiveram medo de dar sua contribuição, mesmo quando não acreditavam muito nela, mostrando o empoderamento e a confiança do grupo. Como no caso em que um aluno disse: "Podemos levar terra para o palco e fazer o cenário do sertão?", e o professor perguntou: "Como vamos limpar para a apresentação do próximo grupo?", fazendo com que o aluno criasse uma nova ideia de cenário: usar um tecido ou $t n t^{8}$ marrom - ainda que, ao final, tenha sido decidido que o material tnt poderia causar algum acidente, pois alguém poderia escorregar, esta possibilidade impediu a utilização desse recurso.

Estabeleceu-se, portanto, na mediação, a flexibilidade, a valorização da relação vincular, o uso de perguntas, a valorização do regional, da criatividade, da inventividade e do empoderamento do grupo para o trabalho colaborativo.

\footnotetext{
${ }^{8}$ Material similar ao tecido.
} 


\section{Etapas da sequência}

Pode-se considerar que a Sequência Fedathi atuou com uma Tomada de Posição ao ajudar os alunos a entenderem a finalidade do teatro, por meio da construção do nome dado à equipe. Além do nome, foi proposto que os alunos escolhessem um texto, realizando outra Tomada de Posição para a fase da escrita, mas a professora precisou replanejar essa estratégia, optando pela escolha do texto e pela readaptação da história original, ou seja, redefinindo o ponto de partida.

Portanto, como Tomada de Posição para a vivência da peça, pontua-se, além da necessidade de adaptar a peça para o teatro, a escolha dos alunos que atuariam em cada papel, considerando-se a forma de falar do personagem e de se portar no espetáculo.

A atividade do teatro científico, como um todo, apresentou mais de uma Tomada de Posição, realizada dentro da capacidade dos alunos e considerando a problemática de se criar um texto, de entender o problema matemático, da própria interpretação e da escolha de personagens.

O problema matemático, considerado como Tomada de Posição, configurou-se quando os personagens do texto tentavam dividir 35 camelos, nas razões $\frac{1}{2}, \frac{1}{3} \mathrm{e} \frac{1}{9}$ entre três irmãos. Os alunos puderam questionar a solução do problema e se surpreenderam com a solução dada pelo personagem principal.

Os alunos indicaram jeitos, comportamentos e apresentaram-se, refazendo e identificando as formas de atuar dos colegas, ressignificando os personagens em constante processo de Maturação e Solução. Ao final das soluções, os alunos já conseguiam visualizar os personagens com maior clareza e era possível decidir em grupo quem atuaria em cada papel.

Os processos de Maturação e Solução aconteceram por mais de uma vez. Os alunos se debruçavam sobre as transformações no texto, e, no desenvolvimento do problema matemático, apresentavam soluções, identificavam as transformações dos colegas e ressignificavam suas próprias transformações, reunindo, com ajuda do professor, seja o texto final ou a solução matemática, realizando a Prova.

A Prova faz referência ao ensaio final e à apresentação do espetáculo. Os caminhos foram valorizados, já que todo o processo constituiu um trabalho de colaboração. O conjunto das ideias para o texto, a sintonia da atuação, a escolha do nome do grupo, com idas e voltas entre as etapas, passou por processo de refinamento, seja na escolha dos personagens durante a peça, seja na descoberta matemática dentro da atividade de elaboração do texto.

\section{Metodologia de pesquisa Sequência Fedathi no planejamento docente}

A Tomada de Posição/Apresentação do Problema, no que se refere à experiência explorada neste artigo, trabalhou o teatro científico, articulando artes e ciências, por meio de uma nova metodologia, acreditando no ganho que professor e aluno poderiam ter com a experiência, pois esse tipo de atividade não é comum na escola.

$\mathrm{Na}$ Tomada de Posição, o professor compreendeu que, para usar a nova metodologia, era preciso modificar sua mediação, portanto, planejou que os próprios alunos participassem de toda a construção, dando uma maior autonomia para os estudantes, exigência da nova prática. Nesse momento, o professor realizou uma sondagem do Plateau dos alunos e construiu as sessões didáticas da aula, ou seja, fez o planejamento de suas ações.

$\mathrm{Na}$ Solução, verificou-se a aplicação do método e a utilização da metodologia de ensino Sequência Fedathi, desse modo, foram percebidas as atitudes dos participantes. O professor aplicou a Metodologia de Ensino Sequência Fedathi à criação do texto, à escolha do nome do grupo, à 
apresentação do problema matemático e à construção da peça, e deixou que o aluno participasse de todo o processo.

Para enfim, na Prova, analisar as aplicações, e constatar que utilizar a nova metodologia, atrelada à ciência, foi algo positivo, pois foi possível perceber o envolvimento dos alunos; a mudança de postura do professor, com a dialogicidade em sala de aula; os sucessos com as premiações do grupo no concurso, entre tantas outras escolas; a movimentação da comunidade escolar com a ajuda dos professores nos dias da apresentação e premiações, resultando também no exposto artigo.

A Tabela 2 explana melhor este trabalho, no que se refere a cada etapa da metodologia de pesquisa Sequência Fedathi. Observa-se os ciclos de construção do texto e os ensaios da peça, que, no momento da aplicação, aconteciam juntos, já que o texto final só ficou definido, simultaneamente, ao fim dos ensaios. Eles foram sempre sendo aprimorados, em constante Maturação, e a Solução, por parte dos alunos com a "pedagogia mão no bolso", foi sendo realizada pelo professor. A sistematização apresentada no quadro é a síntese sobre a experiência com a nova metodologia explorada.

Tabela 2: Passos da Metodologia de Pesquisa Sequência Fedathi realizados no teatro científico

\begin{tabular}{|c|c|c|c|}
\hline $\begin{array}{l}\text { TOMADA DE } \\
\text { POSIÇÃO }\end{array}$ & \multicolumn{3}{|c|}{ Trabalhar o teatro científico com o suporte da metodologia Sequência Fedathi. } \\
\hline MATURAÇÃO & \multicolumn{3}{|c|}{$\begin{array}{l}\text { Objetivo:Articular artes e ciências com os alunos do ensino médio. } \\
\text { Planejamento: } \\
\text { Busca-se estratégias de trabalhar com o teatro científico. } \\
\text { Opta-se pela Construção do texto dos próprios alunos. } \\
\text { Opta-se pela decisão de personagens pelos próprios alunos durante os ensaios. }\end{array}$} \\
\hline \multirow{5}{*}{ SOLUÇÃO } & \multicolumn{3}{|c|}{$\begin{array}{l}\text { Dois ciclos de Fedathi atuam juntos: Criação de textos e ensaios da peça que se } \\
\text { movimentaram juntos até o dia da apresentação. }\end{array}$} \\
\hline & Ciclos: & Texto & Peça \\
\hline & $\begin{array}{c}\text { Tomada de } \\
\text { Posição }\end{array}$ & $\begin{array}{l}\text { Construir o texto com base nas } \\
\text { ideias de regionalização. }\end{array}$ & $\begin{array}{l}\text { Montar ideias e falas de } \\
\text { personagens. Alterar o texto } \\
\text { para o teatro. }\end{array}$ \\
\hline & $\begin{array}{l}\text { Maturação } \\
\text { Solução }\end{array}$ & $\begin{array}{l}\text { Alunos se debruçam sobre o texto, } \\
\text { pensam em palavras, constroem } \\
\text { parágrafos, apresentam, e melhoram, } \\
\text { verificando as ideias. A matemática } \\
\text { do texto é refletida. }\end{array}$ & $\begin{array}{l}\text { Montar ideias e falas de } \\
\text { personagens. Alterar o texto } \\
\text { para o teatro. Criar, apresentar e } \\
\text { refazer. }\end{array}$ \\
\hline & Prova & $\begin{array}{l}\text { Professor reuniu as melhores ideias } \\
\text { e montou, colaborando com o } \\
\text { texto final. }\end{array}$ & $\begin{array}{l}\text { Ensaio final, decisão dos } \\
\text { personagens e apresentação do } \\
\text { espetáculo. }\end{array}$ \\
\hline PROVA & \multicolumn{3}{|c|}{$\begin{array}{l}\text { Analisa-se o que foi feito. } 6 \text { indicações, } 3 \text { prêmios, entre eles melhor texto adaptado, } \\
\text { melhor ator e melhor espetáculo (Júri técnico), confirmando o sucesso dentro do que se } \\
\text { propôs. } \\
\text { A turma de teatro ficou popular na escola, os alunos ficaram motivados e vários outros } \\
\text { alunos quiseram participar de uma próxima edição. } \\
\text { Professores prontificaram-se a ajudar na data do evento e premiação. } \\
\text { O professor responsável percebeu uma postura na prática, sentiu-se motivado, e pôs-se a } \\
\text { refletir sobre os momentos que aconteceram, articulando-os no presente artigo. }\end{array}$} \\
\hline
\end{tabular}

Fonte: Elaborado pelos autores, 2020 
Observa-se na Tabela 2 a utilização tanto da Metodologia de Pesquisa como da Metodologia de Ensino pelo professor, sendo esta última realizada na etapa de Aplicação da Metodologia de Pesquisa. As duas metodologias são necessárias ao professor. A primeira irá tratar de todo o processo para execução de uma atividade. Planejamento, nas etapas de Tomada de Posição e Maturação (Problema e Modelização); execução da atividade com os alunos, na etapa de Solução (Aplicação ou Validação); e avaliação na etapa de Prova (Resultados). Ou seja, a aplicação é o momento de colocar em prática, com os alunos, o que já foi planejado nas fases anteriores, e de usar a metodologia de ensino Sequência Fedathi. Percebe-se que o professor pode estar em constante movimento nessas fases, retornando, por exemplo, para a Maturação, a fim de refazer seu planejamento.

\section{Depoimento dos alunos}

Alguns depoimentos dos alunos, apresentados na Tabela 3, reforçam a importância dessa experiência. Os alunos foram chamados por nome de cearenses que tiveram grande influência no desenvolvimento do país.

Tabela 3: Depoimentos dos alunos

\begin{tabular}{|l|l|}
\hline Dragão do Mar: & $\begin{array}{l}{[\ldots . .] \text { o teatro foi uma válvula de escape, tendo em vista toda a pressão e estresse do }} \\
\text { ensino médio por conta do vestibular [...] entramos como uma brincadeira, e nos } \\
\text { comprometemos ao ponto de ganhar prêmios. }\end{array}$ \\
\hline Jovita Feitosa: & $\begin{array}{l}{[\ldots] \text { a escola em si não dava suporte para o teatro. O último lugar que pensei em }} \\
\text { encontrar essa oportunidade foi na Matemática, mas que bom que foi assim [...] } \\
\text { estou cursando Artes Visuais no IFCE, percebi que posso ser uma arte-educadora. }\end{array}$ \\
\hline $\begin{array}{l}\text { Martim Soares } \\
\text { Moreno: }\end{array}$ & $\begin{array}{l}{[\ldots . .] \text { ensinou grande lições de vida, que devemos nos empenhar no que fazemos, }} \\
\text { dando o nosso melhor em tudo [...] teatro não é só fazer a peça, ganhar troféu, o } \\
\text { teatro em geral é viver aquilo. }\end{array}$ \\
\hline $\begin{array}{l}\text { Bárbara de } \\
\text { Alencar: }\end{array}$ & $\begin{array}{l}\text { os ganhos pessoais com o teatro foram felicidade, experiência, interação, amizades } \\
\text { e amor pela dança [...] quando queremos podemos alcançar, a união faz a força, e } \\
\text { que não devemos deixar que nossos medos interiores nos façam desistir do que } \\
\text { desejamos almejar. }\end{array}$ \\
\hline
\end{tabular}

Fonte: Elaborado pelos autores, 2020.

É possível identificar na fala dos alunos a valorização do processo, como na de Martim Soares Moreno, que reforça a importância de "viver aquilo", importando-se com a construção da vivência e não apenas com o resultado final, ou seja, o "ganhar troféu". Os alunos tiveram a responsabilidade durante todo o trabalho de chegar ao resultado da peça. Eles sabiam que o resultado dependeria do esforço conjunto durante o ensaio. Entre os depoimentos, nota-se a superação do medo, da timidez, da transformação da brincadeira de fazer teatro para a seriedade em alcançar um objetivo. Existe a parceria, a troca, a relação vincular entre os participantes. Atentase, também, para: a matemática como apoio para a arte; a associação da ciência com a atuação; a quebra da seriedade das aulas, sem prejuízo para o rendimento escolar. 


\section{CONCLUSÕES}

É possível considerar que os jovens desenvolveram a sensibilidade, a comunicabilidade, a disciplina, a memória, a dicção e a expressão corporal, além da reflexão do problema matemático apresentado na obra. Ficaram atentos durante um passeio ao teatro para assistir a uma peça e conhecer o local da apresentação, além de terem sido criativos: eles próprios construíram utensílios de apresentação com material reciclável e se encarregaram de ir buscar o figurino num sítio de quadrilha junina, próximo à escola.

A falta de verba foi uma das adversidades superadas. No dia da apresentação, na Seara de Ciências da UFC, alguns professores e o diretor da escola levaram estudantes participantes em seus carros particulares, confirmando a adesão que a escola demonstrou ao projeto do teatro científico. A apresentação resultou em seis indicações e três prêmios: Melhor Texto Adaptado, Melhor Espetáculo (Júri Oficial) e Melhor Ator, ganhando prestígio entre a comunidade escolar, o que estimulou outros jovens a participarem de edições futuras.

A professora, que acreditava que essa nova metodologia poderia ajudar, mas apenas na prática, colocando suas concepções em ação, pôde verificar as transformações ocorridas. Quando precisou reorganizar uma nova Tomada de Posição, ao perceber que os alunos precisariam passar por mais de um ciclo de Maturação e Solução para se chegar ao resultado esperado, colocou-se num constante "refletir-na-ação", valorizando o processo, dando ao aluno a oportunidade de ser responsável, e reaprendendo ainda mais sobre a metodologia que estava utilizando, pensando criticamente sobre ela.

Acredita-se, portanto, que a pergunta inicial "como a Sequência Fedathi pode transformar práticas docentes?" foi respondida positivamente, já que a experiência com a Fedathi trouxe à professora uma flexibilidade no planejamento; deixou que o aluno participasse mais do processo; valorizou a construção e não apenas o resultado final; utilizou-se da dialogicidade em sala de aula; e fortaleceu a confiança dos alunos, mesmo quando precisaram maturar e solucionar problemas, por diversas vezes, fazendo-os entender que a sequência não é algo mecânico, pois possui uma maior flexibilidade entre as etapas, com idas e vindas no processo a fim de se chegar à Prova. A docente compreendeu melhor a dinâmica da sequência, utilizando fortemente não só a metodologia de ensino, como a de pesquisa para o planejamento das ações, colocando-se à disposição para mudanças, se desequilibrando, não se conhecendo na ação, e, sempre, refletindo.

A exploração dessa experiência mostrou que a professora em autoformação foi capaz de proporcionar um momento diferenciado para alunos. Com a imersão nessa metodologia, colheuse subsídios para a elaboração deste artigo, pois foram observadas com mais atenção as interferências feitas no desenvolvimento da experiência, seja para a construção do texto ou da peça.

Não foi só o teatro, foi a mediação com a Sequência Fedathi que gerou os resultados aqui apresentados. A metodologia instigou a forma de atuação do professor, não dando respostas prontas, mas deixando que os alunos participassem dos processos de construção, seja do texto da peça, seja da própria apresentação em si, seja da Matemática envolvida no texto. De fato, é possível se apoiar em várias técnicas de ensino para uma metodologia de elaboração, por exemplo, pode-se utilizar uma peça teatral, uma atividade em grupo, ou uma visita fora da escola, porque os procedimentos metodológicos vão nortear o "como fazer". Não se pode identificar uma única forma de atuar, mas indicar um caminho.

De fato, o teatro foi apenas uma ferramenta, trabalhada no contraturno, com os alunos que se dispuseram, mas a sequência pode garantir na sala de aula regular momentos de envolvimento e maturação com o que se quer trabalhar, independente da ferramenta teatro científico. 
Embora o professor tenha escolhido a obra a ser trabalhada, é interessante deixar que os alunos procurem o texto inicial da peça para fazer as adaptações, dando ao aluno essa responsabilidade, estimulando o processo investigativo.

O professor disposto a mudar coloca-se fora da zona de conforto, a fim de criar uma oportunidade de experimentação para os alunos, e se transforma. Segundo Gauthier, Bissonnette e Richard (2014) o professor é a categoria de maior influência no aprendizado dos alunos. Eles têm vivência com os estudantes e podem melhor compreender o que eles precisam. As iniciativas devem ser valorizadas, portanto, é necessária uma maior movimentação das escolas em apoio às práticas dos professores.

O texto completo da peça pode ser encontrado na edição de 2017 da revista "Seara Teatral: Festival de teatro científico da Seara da Ciência". No Youtube, pode ser encontrada toda a apresentação?.

Diante do exposto, recomenda-se uma formação inicial e continuada na aplicação da Sequência Fedathi, para que vários professores possam utilizar essa metodologia em sala de aula. Seja qual for a técnica utilizada, a fim de reconstruir concepções de ensino e aprendizagem, é possível aliar técnicas de ensino a uma metodologia transformadora, seja uma aula expositiva, uma peça de teatro. Independentemente da especialidade do professor, esta aliança (de técnicas de ensino com uma metodologia transformadora) pode proporcionar momentos de reflexão da prática, a fim de atender inúmeros docentes que atuam em sala de aula e sentem a necessidade de inovar em suas aulas.

É necessário que a formação “[...] não conceba o professor como um mero executor qualificado de tarefas pré-figuradas" (HECKERT, ALGEBAILE, 2002, p. 11). É preciso planejar, refletir com a comunidade escolar sobre os feitos para melhorar os índices das disciplinas, tendo uma nova perspectiva, uma nova forma de mediar, proporcionando ao aluno responsabilidades no seu processo de aprendizagem. Não se indica uma técnica, mas uma metodologia eficiente para sua abordagem. Indica-se, portanto, a Formação Fedathi Generalizada, uma formação vivencial da Sequência Fedathi para professores de diversas áreas, a fim de internalizar conceitos e vivenciar na prática a sequência. "[...] não existe um botão liga/desliga a mediação com a Sequência Fedathi" (FELÍCIO, MENEZES, BORGES NETO, 2000, p. 38), o processo deve ser amadurecido: conhece-se a sequência, planeja-se a aula com o viés fedathiano, aplica-se e avalia-se, num ciclo de constante amadurecimento e de mudança de prática.

\section{REFERÊNCIAS}

BARBOSA, Jéssica de Castro. Raízes: Concepcões Teóricas, pedagógicas e tecno- práticas de um objeto educacional digital (OED) baseado na Sequência Fedathi. 93f. Dissertação (Mestrado em Educação), Programa de Pós-graduação em Educação, Faculdade de Educação, Universidade Federal do Ceará, Fortaleza, 2020. Disponível em http://www.repositorio.ufc.br/handle/riufc/52836. Acesso em 10 set. 2020.

BAUER, Martin W; GASKELL, George. Pesquisa qualitativa com texto, imagem e som: Um manual prático. Petrópolis: Editora Vozes, 2015.

BORGES NETO, Hermínio Borges; Uma proposta lógico-dedutiva-construtiva para o ensino de matemática. 28f. Tese (Professor titular), Faculdade de Educação, Universidade Federal do Ceará, Fortaleza,

\footnotetext{
${ }^{9}$ Cf. https://www.youtube.com/watch?v=QIJgPBblWc0https://www.youtube.com/watch?v=QIJgPBbIWc0.
} 
2016. Disponível em http://blogs.multimeios.ufc.br/wp-content/uploads/2020/11/tese-titularfaced-2016-hbn.pdf. Acesso em 10 ago. 2020.

BRANCA, Tenê de Casa; Teatro Para quem nunca fez teatro. São Paulo: Global editora, 2007.

BRANDÃO, Carlos Rodrigues. R; STRECK, Danilo Romeu. Pesquisa participante: o saber da partilha. São Paulo: Ideias e Letras, 2006.

FELÍCIO, Milínia Stephanie Nogueira Barbosa; MENEZES, Daniel Brandão; BORGES NETO, Hermínio. Formação Fedathi Generalizável: Metodologia de Formação de Professores, Boletim Cearense de Educação e História da Matemática, Fortaleza, v. 7, n. 19, p. 24-40, abr. 2020. Disponível em https://revistas.uece.br/index.php/BOCEHM/article/view/2906/2550. Acesso em 10 ago. 2020.

FERRAZ, Ana Paula do Carmo Marchet; BELHOT, Renato Vairo. Taxonomia de Bloom: revisão teórica e apresentação das adequações do instrumento para definição de objetivos instrucionais. Gestão \& Produção, São Carlos, v. 17, n. 2, p. 421-431, 2010. Disponível em https://www.scielo.br/scielo.php?pid=S0104-

530X2010000200015\&script=sci abstract\&tlng=pt. Acesso em 10 ago. 2020.

FONTENELE, Francisca Cláudia Fernandes. Contribuições da Sequência Fedathi para o desenvolvimento do Pensamento Matemático Avançado: uma análise da mediação docente em aulas de álgebra linear. 192f. Tese (Doutorado em Educação), Programa de Pós-graduação em Educação, Faculdade de Educação, Universidade Federal do Ceará, Fortaleza, 2018. Disponível em http://www.repositorio.ufc.br/handle/riufc/37490. Acesso em 10 ago. 2020.

FRANCO, Maria Amélia do Rosario Santoro. Prática pedagógica e docência: um olhar a partir da epistemologia do conceito. Estudos RBEP, Brasília, v. 97, n. 247, p. 534-551. 2016. Disponível em https://www.scielo.br/scielo.php?pid=S2176-

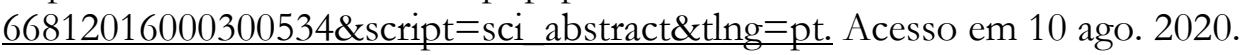

GAUTHIER, Clermont; BISSONNETTE, Steve; RICHARD, Mario. Ensino explícito e desempenho dos alunos: a gestão dos aprendizados. Petrópolis: Editora Vozes, 2014.

GIL, Antônio Carlos. Métodos e Técnicas de Pesquisa Social. São Paulo: Atlas, 2008.

HARGREAVES, Andy et al. Aprendendo a mudar: o ensino para além dos conteúdos e da padronização. Porto Alegre: Artmed, 2002. Disponível em http://portal.mec.gov.br/seb/arquivos/pdf/volla.pdf. Acesso em 10 ago. 2020.

HARGREAVES, Andy; CONNOR. Michael. T. O. Leading ollaborative professionalism. Victória: Centre for Strategic Education Seminar Series Paper. 2018. Disponível em http://www.andyhargreaves.com/uploads/5/2/9/2/5292616/seminar series 274-april2018.pdf. Acesso em 10 ago. 2020.

HECKERT, Ana Lúcia C. Heckert; ALGEBAILE, Eveline Bertino. Formação e mudança: reflexões compartilhadas. Revista Teias, v. 3, n. 5, p. 13, jan./jun. 2002. Disponível em https://www.e-publicacoes.uerj.br/index.php/revistateias/article/view/23909/16882. Acesso em 10 ago. 2020.

HOFFMANN, Jussara. Avaliação mediadora: uma prática em construção da pré-escola à universidade. Porto Alegre: Mediação, 2009.

LAKATOS, Imre. A lógica do descobrimento matemático: provas e refutações. Rio de janeiro: Zahar Editores, 1978. 
DOI: $10.12957 /$ teias.\%Y.50751

LOPES; Antônia Osima. Aula expositiva: superando o tradicional. In: VEIGA, Ilma Passos Alencastro et al. (org.). Técnicas de ensino: por que não? Campinas, SP: Papirus, 2011.

MAGALHÃES, Pedro Jorge Caldas et al. (org.). Seara Teatral: festival de teatro cientifico da Seara da Ciência. Fortaleza: Seara da Ciência Publicações, 2017.

MARCHESI, Álvaro. Educação para mudança. In: Congresso Brasileiro de Qualidade na Educação: formação de professores. 2002, Brasília: MEC, SEF, 2002. p. 17-23. Disponível em http://portal.mec.gov.br/seb/arquivos/pdf/vol1a.pdf. Acesso em 10 ago. 2020.

MENEZES, Daniel Brandão. O Ensino do Cálculo Diferencial e Integral na perspectiva da Sequência Fedatbi: Caracterização do comportamento de um bom professor. 128 f. Tese (Doutorado em Educação), Programa de Pós-graduação em Educação, Faculdade de Educação, Universidade Federal do Ceará, Fortaleza, 2018.2 Disponível em http://repositorio.ufc.br/bitstream/riufc/37124/1/2018 tese dbmenezes.pdf. Acesso em 10 ago. 2020

PIAGET, Jean. A epistemologia genética. São Paulo: Victor Civita, 1983.

PINHEIRO, Ana Cláudia Mendonça. Concepção e desenvolvimento de uma formação continuada de professores de matemática baseado na sequência Fedathi. 138f. Tese (Doutorado em Educação), Programa de Pósgraduação em Educação, Universidade Federal do Ceará, Fortaleza, 2016. Disponível em http://repositorio.ufc.br/handle/riufc/44839. Acesso em 10 ago. 2020.

PINHEIRO, Ana Cláudia Mendonça. A Mediação. In: BORGES NETO, Hermínio. (org.) Sequência Fedathi: Fundamentos. Curitiba: CRV, 2018.

POLYA, George. A arte de resolver problemas. Rio de Janeiro: Editora Interciência, 2006.

RONCA, Antônio Carlos Caruso et al. Os desafios da educação brasileira no século XXI. São Paulo: CIEE, 1998.

SCHÖN, Donald. A. Educando o profissional reflexivo: um novo design para o ensino e a aprendizagem. Porto Alegre: Artmed, 2000.

SOUSA, Francisco Edisom Eugenio. A pergunta como estratégia de mediação didática no ensino de matemática por meio da Sequência Fedathi. 258f. Tese (Doutorado em Educação), Programa de Pósgraduação em Educação, Universidade Federal do Ceará, Fortaleza (CE), 2015. Disponível em http://www.repositorio.ufc.br/handle/riufc/14363. Acesso em 10 ago. 2020.

TAHAN, Malba. O bomem que calculava. Rio de Janeiro: Record, 2008.

TREVIZAN, Zizi; GEBRAN, Raimunda Abou; GUIMARÃES, Cléber Ferreira. A mediação docente no ensino da leitura literária. Revista Teias, v. 18, n. 49, p. 181-193, abr./jun. 2017. Disponível em https://www.epublicacoes.uerj.br/index.php/revistateias/article/view/26708/20960. Acesso em 10 ago. 2020.

XAVIER, Daniele de Oliveira. Raízes: postura docente virtual a partir de uma perspectiva Fedathiana. 88f. Dissertação (Mestrado em Educação), Programa de Pós-graduação em Educação, Faculdade de Educação, Universidade Federal do Ceará, Fortaleza, 2020. Disponível em http://www.repositorio.ufc.br/handle/riufc/52835. Acesso em 10 set. 2020.

YIN, Robert K. Estudo de caso: planejamento e métodos. Porto Alegre: Bookman, 2010

ZEICHNER, Kenneth. M. A formação reflexiva de professores: Ideias e Práticas. Lisboa: Educa, 1993. 
DOI: $10.12957 /$ teias.\%Y.50751

Submetido em maio de 2020

Aprovado em novembro de 2020

\section{Informações dos autores}

Milínia Stephanie Nogueira Barbosa Felício

Universidade Federal do Ceará

E-mail:milinia@multimeios.ufc.br

ORCID: https://orcid.org/0000-0003-1130-6374

Link Lattes: http://lattes.cnpq.br/0567964138512463

Daniel Brandão Menezes

Universidade Estadual Vale do Acaraú

E-mail: danielbrandao@multimeios.ufc.br

ORCID: https://orcid.org/0000-0002-5930-7969

Link Lattes: http://lattes.cnpq.br/8450083821283590

Hermínio Borges Neto

Universidade Federal do Ceará

E-mail: herminio@multimeios.ufc.br

ORCID: https://orcid.org/0000-0003-4854-6953

Link Lattes: http://lattes.cnpq.br/6933091154844634 